\begin{tabular}{|c|c|c|}
\hline $\begin{array}{l}\text { PUCRS } \\
\text { PUC. }\end{array}$ & $\begin{array}{l}\text { ESCOLA DE } \\
\text { HUMANIDADES }\end{array}$ & $\begin{array}{l}\text { Revista Digital do Programa de Pós-Graduação em Letras da PUCRS } \\
\text { Letrônica, Porto Alegre, v. 13, n. 1, p. 1-10, jan.-mar. } 2020 \\
\text { e-ISSN: } 1984-4301\end{array}$ \\
\hline de) $\mathrm{http}: / / \mathrm{dx}$ & org $/ 10.15448 / 1984-4301.2020 .1 .35138$ & \\
\hline
\end{tabular}

\title{
Memória por correspondência: as cartas da artista colombiana Emma Reyes na rememoração da infância
}

\author{
The Book of Emma Reyes: the letters of the Colombian artist \\ Emma Reyes in remembrance of her childhood \\ Memoria por correspondencia: las cartas de la artista colombiana \\ Emma Reyes en la rememoración de su infancia
}

\section{Nathália Hecz Couto ${ }^{1}$ \\ orcid.org/0000-0002-5629-0794} nathalia.couto@edu.pucrs.br

Recebido em: 30 jul. 2019. Aprovado em: 24 set. 2019 Publicado em: 7 abr. 2020.

\section{(C) (1)}

Artigo está licenciado sob forma de uma licença Creative Commons Atribuição 4.0 Internacional.
Resumo: A partir da leitura do livro Memória por correspondência, de Emma Reyes, é possivel conhecer a história de vida da artista colombiana, a qual se destaca, no presente artigo, como uma figura relevante no contexto de literatura escrita por mulheres na América Latina. Desse modo, com este trabalho, pretende-se discutir a respeito de algumas chaves de leitura presentes no conjunto de cartas de autoria de Emma, com base no aporte teórico de autores como Aleida Assmann (2011) e Paul Ricoeur (2007). Antes que se entre nos aspectos de análise. serão apresentadas informações a respeito do surgimento dessa obra, bem como dados biográficos da autora, de acordo com o respaldo do trabalho jornalístico de Diego Garzón (2016), a fim de que mais reflexões possam ser estabelecidas a partir desta breve proposta de estudo. Por fim, apresentam-se, como chaves de leitura, a memória cultural e a identidade, os espaços e as vozes que aparecem na narrativa, por meio das memórias.

Palavras-chave: Literatura colombiana. Memória por correspondência. Emma Reyes. Memória.

Abstract: From the reading of The Book of Emma Reyes: A Memoir, by the Colombian artist Emma Reyes, it is possible to know the author's life story. She stands out in this article as a relevant figure in the context of literature written by women in Latin America. Thus, this paper aims to discuss the possible reading keys presented in Emma's set of letters, based on the theoretical background of authors such as Aleida Assmann (2011) and Paul Ricoeur (2007). Before starting the analysis and considering its aspects, some information about the emergence of this work will be presented, as well as the biographical data of the author, according to Diego Garzón's (2016) journalistic work, in order to establish more reflections from this study proposal. Finally, the reading keys presented are cultural memory and identity, spaces and voices that appear in the narrative through memoirs. Keywords: Colombian literature. The Book of Emma Reyes. Emma Reyes. Memoir.

Resumen: A partir de la lectura del libro Memoria por Correspondencia, de Emma Reyes, es posible conocer la historia de vida de la artista colombiana, quien se distingue, en este artículo, por ser una figura relevante en el contexto de la literatura escrita por mujeres en América Latina. De esa manera, con este trabajo, se busca discutir algunas claves de lectura en el conjunto de cartas de autoria de Emma, con base en el aporte teórico de autores como Aleida Assmann (2011) y Paul Ricoeur (2007). Antes de los aspectos de análisis, se presentan informaciones sobre el surgimiento de la obra y datos biográficos de la autora, según lo que expone el trabajo periodistico de Diego Garzón (2016), para que se produzcan más reflexiones en el marco de esta breve propuesta de investigación. Por fin, se exponen, como claves de lectura, la memoria cultural y la identidad, los espacios y a las voces que aparecen en la narrativa, a través de las memorias.

Palabras clave: Literatura colombiana. Memoria por correspondencia. Emma Reyes. Memoria. 


\section{Introdução}

Em Memória por correspondência, publicaram-se 23 cartas, escritas entre 1969 e 1997, enviadas pela artista plástica colombiana a seu amigo Germán Arciniegas. Esse, ensaista, diplomata e historiador, foi quem motivou Emma a que contasse a sua infância por meio da narrativa epistolar, já que the custava falar sobre o assunto. Contudo, a pintora interrompeu a escrita depois de saber que o seu amigo havia apresentado o material a Gabriel Garcia Marquez, o qual mostrou-se impressionado com as histórias narradas². Logo, pediu que Germán incentivasse a autora a continuar a escrever as missivas. Felizmente, anos mais tarde, Emma retomou as suas memórias e seguiu o seu relato.

As cartas, que permaneceram sob os cuidados da familia Arciniegas, foram publicadas, por vontade expressa da autora, somente após o seu falecimento. Quanto ao conjunto de textos, reúne memórias de infância, desde lembranças mais remotas, em um bairro pobre de Bogotá, até o momento em que Emma conseguiu fugir do convento em que viveu por muitos anos. $\mathrm{Na}$ carta $n .{ }^{\circ}$, há uma passagem em que ela se manifesta sobre o peso que essas recordações tiveram em relação ao porvir:

Se é verdade que há fatos de nossa infância que nos marcam a vida inteira, devo dizer que que essa famosa carroça que nos separou da casinha no bairro de San Cristóbal (padroeiro dos viajantes) para sempre foi o começo de uma vida que teria como simbolo e como escola a inclemência dos duros caminhos da América e, mais tarde, dos fabulosos caminhos da Europa (REYES, 2016, p. 29).

Ao final da edição da obra utilizada para este trabalho, encontra-se o artigo O que aconteceu com Emma Reyes, de autoria do jornalista Diego Garzón. É nesse material que estão fundamentadas as informações aqui apresentadas a respeito da vida pessoal da artista, excedendo-se, assim, o marco traçado por Emma na última carta publicada. Cabe salientar que Diego, diretor e editor da revista colombiana SoHo, obteve o Premio Nacional de
Periodismo Simón Bolivar de melhor crônica e reportagem na categoria de imprensa, no ano de 2013, pelo trabalho publicado sobre Emma Reyes. De acordo com a descrição referente ao agraciado no site oficial do prêmio mencionado3, a crônica de Garzón apresenta uma perspectiva pessoal a respeito da pintora, revelando a metade da vida de Emma Reyes que não apareceu em suas memórias, por meio de uma investigação baseada em entrevistas e em fontes documentais.

Conforme o relato publicado na revista SoHo, Emma viajou por toda a América Latina. Após a sua fuga para o "mundo", como era referida a vida fora das paredes da comunidade religiosa em que esteve, trabalhou em uma emissora e em um hotel de Bogotá, onde aprendeu a ler e a escrever com os diplomatas que frequentavam o lugar. No Uruguai, na década de 1940, conheceu Guillermo Botero Gutiérrez, escultor com quem se casou. Depois, chegaram ao Paraguai, que vivia ainda sob a sombra da Guerra da Triplice Aliança. Fala-se, também, sobre o único filho da autora, morto por um grupo de homens que invadiram sua casa para saqueá-la, em uma das revoltas motivadas pela guerra (GARZÓN, 2016, p. 195).

Em Buenos Aires, ganhou uma bolsa de estudos para ir a Paris, o que motivou o fim da união com Botero. Posteriormente, ela viajou para vários lugares, ainda pobre, em busca de uma carreira como pintora. Dessa forma, passou por Washington, contratada pela United Nations Educational, Scientific and Cultural Organization (Unesco), com o objetivo de fazer as cartilhas de alfabetização para a América Latina. Trabalhou com Diego Rivera, no México e, após, foi a Roma. Depois da convivência com intelectuais italianos, "graças a sua pintura e a seu carisma" (GARZÓN. 2016, p. 199), viajou a fim de vender as suas pinturas, com dificuldades, chegando, inclusive, a trabalhar como motorista de uma marquesa. Após alguns infortúnios, instalou-se definitivamente na França, em 1960. Jean Perromat, um médico francês, foi seu segundo marido. Emma faleceu em Bordeaux, no ano de 2003, aos 84 anos.

\footnotetext{
2 Essa informação pode ser encontrada em matéria escrita pelo escritor português José Riço Direitinho, publicada na Revista İpsilon, em 2017, sob o título A incrivel e triste história de Emma Reyes e das freiras desalmadas.

3 Disponivel em: https://www.premiosimonbolivar.com. Acesso em: 20 jul. 2020.
} 
Em vida, a artista esclareceu que o seu dinheiro deveria ser doado a um orfanato colombiano, bem como o valor de royalties arrecadado em razão da publicação de seu livro Memória por correspondência. Com essa atitude, Emma conseguiu, à sua maneira, prestar auxilio às crianças que passaram por dificuldades assim como ela (GARZÓN, 2016, p. 206). A fundação, situada em San José de Bavaria, constitui-se de alojamentos para as quase 150 crianças que lá estavam abrigadas quando da visita de Diego Garzón. De acordo com o relato do jornalista, o local é decorado com pinturas e cartazes infantis, contando, ainda, com um jardim de infância. No trecho a seguir, apresenta-se o comentário de Garzón sobre a instituição:

Chegam menores abandonados, maltratados, e a fundação os acolhe para educá-los, alimentá-los, dar-lhes um canto para dormir. Há bebês de alguns meses num quarto separado, à espera de adoção. Como em todo trabalho desse tipo, sempre faltam recursos, mas o esforço para lhes proporcionar uma infância digna é evidente. Vejo as crianças brincado no gramado, correndo, rindo: todas são Emma. Essa infância triste que ela deixou registrada, tão dificil de esquecer, não foi em vão. Ela ficaria feliz de ver que ajudou essas crianças de alguma forma, cuidadas e protegidas por pessoas que procuraram ser suas familias. São crianças que não sabem quem foi Emma Reyes e que talvez também sonhem com o mundo (GARZÓN, 2016, p. 206-207).

A coletânea de cartas é produto de mais dez anos de pesquisa e de dedicação à preservação do trabalho e das memórias da artista, conforme texto de apresentação da edição utilizada, assinada por Juan Camilo Otero Herrera, coeditor da Fundación Arte Vivo Otero Herrera. A instituição, cujo objetivo é conservar e difundir a arte colombiana, é responsável pelo acervo pictórico e documental de Emma. A respeito dessa recuperação da memória individual e também coletiva, considerando que se trata de recordações de determinada sociedade, tornase pertinente o seguinte pensamento proposto por Aleida Assmann (2011, p. 70): "definimo-nos a partir do que lembramos e esquecemos juntos."

A partir dessa ideia de conservação da memória cultural, enfatiza-se a necessidade de que sejam realizadas ações efetiva sem relação à sua sobrevivência, pois essa memória não se mantém sozinha. Portanto, a preservação da produção artística de Reyes veio a contribuir para o estabelecimento de traços de uma identidade nacional, principalmente por meio de seus relatos, que mostram características da sociedade colombiana na época de sua infância, com as marcas deixadas pela dinâmica desigual das classes sociais.

No prólogo da obra, Piedad Bonnett, poeta e dramaturga, comenta que Emma, além de relatar sua vida, retratou a "Colômbia discriminatória e classista na qual viveu sua infância, na década de 1930, e que não é tão diferente da Colômbia de hoje". De fato, as lembranças encontradas nessas cartas são impregnadas de orfandade e de pobreza, desde quando Emma e Helena estavam sob responsabilidade da mulher que as abandonou até os anos vividos no convento. Segundo Bonnett, "o mundo sombrio das comunidades religiosas era igualmente contaminado por discriminação social, machismo e crueldade, infestado de superstições e preconceitos" (2016, p. 11)

Na carta n. ${ }^{\circ}$, de 28 de abril de 1969, a autora comenta sobre a "lembrança mais remota de sua infância" (REYES, 2016, p. 15). Ao descrever o cômodo em que morava em um bairro popular de Bogotá, San Cristóbal, relatam-se fatos que evidenciam as condições extremas enfrentadas, sem luz elétrica nem mesmo banheiro. Para o leitor, esse primeiro contato com o entorno da personagem já impressiona, não só pela riqueza de detalhes, mas, principalmente, pela crueza da situação em que vivia uma menina de apenas quatro anos.

Após contar sobre o tempo em que viveu em San Cristóbal, outros locais são mencionados, antes da chegada ao convento, como a casa de Guateque, um hotel miserável na Estación de la Sabana e um teatro em Fusagasugá. Todos esses lugares parecem ser relevantes para Reyes, sendo recordados e descritos em associação com o relato de fatos marcantes para sua infância, em companhia da irmã. Conforme Paul Ricoeur (2007, p. 59):

Os lugares habitados são, por excelência, memoráveis. Por estar a lembrança tão ligada a 
eles, a memória declarativa se compraz em evocá-los e descrevê-los. Quanto a nossos deslocamentos, os lugares sucessivamente percorridos servem de reminders aos episódios que aí ocorreram. São eles que, a posteriori, nos parecem hospitaleiros ou não, numa palavra, habitáveis.

Para citar a noção de reflexividade e de mundanidade, (RICOEUR, 2007, p. 53), na perspectiva da fenomenologia da memória, pode-se aproximar a ideia de que não recordamos apenas o que se vive, o que se aprende ou o que se escuta; os lugares e as situações vivenciadas também se dotam de importância. Portanto, entende-se que, a partir dos locais recordados pela autora, as memórias vão se construindo e sendo trazidas à tona, ganhando relevância para a sua formação pessoal.

Dos espaços apresentados, o convento recebe maior atenção na narrativa. Considerando que Emma viveu por mais de dez anos enclausurada nesse local, presume-se que esse tempo passado tenha sido crucial para a construção de sua identidade e, consequentemente, para a formação de suas memórias. Nessa comunidade religiosa, pouco ou quase nada melhorou para as irmãs, pois foram acolhidas como força de trabalho em jornadas de mais de dez horas, com castigos e um rígido regulamento:

a nossa vida estava direcionada a dois únicos e simultâneos objetivos: trabalhar o máximo para ganhar o que comíamos e, segundo as freiras, salvar nossas almas, protegendo-nos dos pecados do mundo (REYES, 2016, p. 98).

Conforme passagens do livro, reforça-se o fato de que a comunidade religiosa não se tratava de um orfanato, mas sim de um local que abrigava meninas pobres, ainda que tivessem família. Em troca, a instituição recebia uma mensalidade de dez pesos de quem podia pagar. As crianças órfãs e as que não tinham condições também eram aceitas, mas, em compensação, tinham de entregar tudo o que produziam com seu trabalho às freiras. A convivência com as colegas e a adaptação foram difíceis, de acordo com a carta $\mathrm{n}^{\circ} 13$, na qual se diz que as outras meninas tiravam vantagem da ignorância das novatas para agirem com crueldade (REYES, 2016, p. 93).

Voltando-nos às passagens que se referem a eventos narrados como memórias propriamente ditas, vejamos um exemplo. Na segunda carta, ao ser perguntada sobre o nome da moça de cabelo comprido, mencionada no primeiro texto, Emma (2016, p. 20) confessa a Germán que "as lembranças são confusas" e que conseguiu chegar à "certa uniformidade de impressões" com a ajuda de sua irmã, dois anos mais velha. Em passagens como essa, nota-se que Emma Reyes realiza um exercício de reflexão sobre o próprio processo de recordação.

Já na carta $n .{ }^{\circ} 10$, a autora fala sobre a estranheza causada por se lembrar de coisas que aconteceram quando era muito pequena, reforçando que isso se deve ao fato de que considera que não viveu uma infância normal, junto de Helena:

Deve the parecer estranho que eu consiga relatar com detalhes e com tamanha precisão acontecimentos de uma época tão distante. Assim como você, também acho que uma criança de cinco anos que leva uma vida normal não conseguiria reproduzir a própria infância com a mesma fidelidade. Tanto Helena quanto eu nos lembramos da nossa infância como se fosse hoje, e não sei explicar a razão. Nada nos escapava: nem gestos, nem palavras, nem ruídos, nem cores; tudo estava claro para nós (REYES, 2016, p. 70).

Ao pensar no que seria de fato uma infância normal, evidencia-se o contraste em relação a essa fase na vida de Emma. Sem vínculos familiares, com pouca comida e quase nenhum afeto, a garota teve de presenciar momentos de abandono de outras crianças que também viviam com ela, além de ter de lidar com o seu. Na carta em que conta sobre o dia em que María levou o menino Eduardo para que não mais voltasse, narra-se o significado dessa memória para ela:

Acho que nesse instante, de uma tacada só, aprendi o que é injustiça e descobri que uma criança de quatro anos já pode sentir vontade de não querer viver mais e de ser devorada pelas entranhas da terra. Esse dia ficará na minha memória como o mais cruel da minha existência, sem dúvida [...]. Não me lembro dos detalhes porque certamente não tinha mais interesse pela vida. A primeira viagem representara o abandono de Eduardo; a segunda, o abandono do Menino (REYES, 2016, p. 58). 
Observa-se, então, que, além do abandono de alguém, cada viagem feita por María e, mais tarde, pelas irmãs, configura também uma perda importante de vínculos, por precários que fossem. Emma não tinha uma estrutura familiar, tampouco sabia quem eram seus pais. Sendo assim, por mais que não soubesse quem exatamente eram as pessoas com quem vivia, essas representavam uma certa referência em sua vida.

Pouco a pouco, foi perdendo todas elas, até contar somente com Helena, a qual também foi se afastando após a chegada ao convento. Dessa forma, o deslocamento estaria ligado a perdas e a abandonos, com a culminação em chegadas a espaços desconhecidos. Esses, conforme citados anteriormente, ganhariam relevância para a identidade de Emma e, portanto, moldariam sua trajetória contada em forma de texto.

Para citar o componente pictográfico da obra literária em análise, salienta-se que as epistolas foram publicadas com treze desenhos de Reyes, enviados por ela a seu destinatário, em diferentes datas. De acordo com Ricardo Sánchez Ángel (2013, p. 361), professor na Universidad Nacional de Colombia, esses desenhos parecem fantasmas da infância de Emma, com a representação de figuras duras, que não expressam ternura, mas sim a presença de uma infância abandonada. Contudo, Ángel salienta, de acordo com sua interpretação, que há duas imagens que fogem à mencionada percepção: a figura que acompanha a carta $n^{\circ} 12$, em que uma mulher carrega uma criança; a outra, que está logo após a última carta, com a representação do abraço entre uma jovem e um homem. Pode-se ver, ainda, um retrato de Emma, pintado por seu amigo Alejo VidalQuadras, em Paris, no ano de 1949.

O livro materializa, assim, o encontro da artista, da escritora e da menina que aprendeu a escrever apenas aos dezoito anos de idade. Por meio das palavras de uma Emma adulta, a narrativa se desenvolve com a simplicidade dos olhos da menina que um dia foi. Segundo Doménico Chiappe (2017, p. 116, tradução nossa), escritor e jornalista peruano, em resenha de Memórias por correspondência:
[...] existe uma convergência de vozes nas cartas em que Emma Reyes recorda sua infância e adolescência, e que enviou a Germán Arciniegas [...]. São as evocações da mulher adulta, sim, como narradora, na qual se podem ver gestualidade, risos e silêncios. Mas há nela outra voz, que sussurra tímida. É a menina que foi e que renasce como protagonista quando a autora rebusca as imagens mais remotas de sua vida para exteriorizá-las, tirá-las dessa caverna e dar-lhes outra forma com palavras.

A partir desse ponto de vista, a dona dessas memórias dá voz à menina, sem que a maturidade e o julgamento adquiridos na vida adulta interferissem na essência da narração da reconstrução dessa infância dura e difícil. Por meio de uma escrita clara e honesta, Reyes descreve o que viveu sem a intenção de provocar tristeza ou pena. Ainda nas palavras de Chiappe (2017, p. 116), "aquela tristeza é como uma sombra, que está ali, mas que não se deixa ver".

Essa convergência de vozes pode ser sentida a cada carta, através das palavras de uma Emma adulta, que recorda a dificuldade de tudo que viveu, através do olhar da menina, que transparece a inocência de quem toma como normais as coisas duras que lhe acontecem, por não conhecer outra vida que não essa. O renascimento da criança e da adolescente, por meio das cartas, possibilita essa confrontação de Emma consigo mesma. Portanto, como testemunha desse processo, o leitor poderá ouvir a voz de uma mulher que se deixa levar pelas impressões da menina, a qual deixa à sombra a sabedoria da mulher adulta.

É com essa forma narrativa que Emma Reyes demonstra sua destreza e talento para manejar as palavras, de modo a desmascarar o que havia por trás do que estava à margem da sociedade colombiana, mostrando problemas relacionados ao tráfico infantil, à negligência, ao racismo e ao machismo. Destacam-se, também, os horrores provocados pela hipocrisia arraigada nos âmbitos social e religioso.

A forma como a religião católica é retratada nos relatos mostra ao leitor a percepção de uma menina diante da criação de um mundo afastado do real, marcado pela clausura e pelos excessos praticados na condução da vida de crianças que eram forçadas a trabalhar em benefício da própria 
instituição, além da distorção da fé pregada. Apesar de todos os infortúnios e injustiças, a menina que existia em Emma Reyes narra o que estava ao seu redor com pureza e inocência, valendo-se de certos fatos já conhecidos por um adulto, conforme a seguinte passagem: "O guapo era de um lugar chamado Espanha, e foi esse pessoal da Espanha que nos trouxe Deus, Maria e todos os santos que tínhamos na capela" (REYES, 2016, p. 175).

Ao falar da origem do padre, o qual chamavam de guapo, e dos elementos religiosos conhecidos por ela, denota-se uma certa ironia, pois o texto confere benevolência à situação, considerando o contexto em que vivia Emma e a maneira como compreendia a religião. Porém, sabe-se que o processo de colonização em territórios pré-hispânicos não se deu de maneira pacífica, contando com a forte atuação da Igreja Católica na cristianização dos nativos, com a missão de "apressar a submissão e a europeização dos indios e pregar a lealdade à Coroa de Castela" (BARNADAS, 1997, p. 521).

Na carta n. ${ }^{\circ}$ 12, fala-se do início da vida no convento e de como as freiras mencionavam dogmas associados ao pecado e ao céu, ao inferno e à salvação de almas, com ênfase no vazio de significado que tudo isso representava para as internas:

[...] todo esse palavreado e mais as orações em latim e as frases "no mundo", "para o mundo", "vem do mundo", como música de fundo eterna, porque tudo que acontecia no convento não acontecia no mundo... Não. Tudo era mundo, menos nós... não podiamos pedir explicação de nada; mundo era pecado e ponto final. Por isso, nas nossas orações, tanto na hora de começar a trabalhar como à noite, sempre rezávamos algumas ave-marias pelos nossos clientes pecadores que nos beneficiavam com suas encomendas para podermos comer e salvar nossas almas (REYES, 2016, p. 100).

Conforme análise de Ángela Uribe Botero (2016), em artigo sobre Memórias por correspondência, o termo palavreado abarca a referência às orações em latim, às rotinas de práticas religiosas, aos discursos e aos cantos, por meio dos quais a incompreensão levava ao respeito alcançado pelo medo. Sendo assim, o contexto em que estavam inseridas era impregnado de um discurso religioso que se propagava através do temor, reafirmando a falsa caridade praticada pela instituição. Nas palavras de Emma: "Foi nessa época que aprendemos o que era a profunda solidão e a ausência de qualquer afeto" (REYES, 2016, p. 91).

Relembra-se, como exemplo da concretização da voz da adulta de Emma Reyes, o momento em que ela se sente injustiçada por não poder realizar, com Helena, a Primeira Comunhão no convento com o mesmo vestido branco que outras meninas, abastadas, vestiram: "Nesse dia, percebi com clareza que no convento - assim como no mundo, como constatei mais tarde a humanidade se divide em classes sociais, e - poder é exclusivo das classes privilegiadas" (REYES, 2016, p. 144). Sendo assim, na clausura dessa comunidade religiosa, Emma viveu na pele as desigualdades desde o momento em que chegou, com a irmã, até o dia em que saiu, sozinha. Afinal, como disse uma das freiras, elas estavam lá por caridade e precisavam trabalhar para pagar o que comiam.

Além das tarefas domésticas, as meninas ainda trabalhavam nas oficinas de bordado. Essa atividade era considerada a mais importante e lucrativa, pois a instituição recebia encomendas de clientes ricos, sacerdotes e militares. Depois de algum tempo, Emma passou a gostar de bordar, pois era algo que estimulava sua imaginação:

\begin{abstract}
Por causa dessa superioridade de Helena, acabei desenvolvendo um verdadeiro complexo. Eu detestava aprender o que quer que fosse; só gostava de inventar histórias, imaginar coisas. Em lugar do catecismo e da aritmética, gostaria mais que me deixassem tocar piano e harmônio e subir nas árvores do quintal; preferia pensar nas histórias de Tarrarrurra a pensar nas da História Sagrada. De bordar eu gostava, porque podia inventar novos pontos e novas maneiras de aplicá-los (REYES, 2016, p. 42).
\end{abstract}

A partir desse trecho, torna-se relevante refletir a respeito do tipo de sujeito construido na narrativa. Em suas recordações, Emma não estabelece nenhum tipo de relação com a atividade da escrita, já que, conforme explicitado na obra, não sabia escrever. Conforme a passagem citada acima, a menina Emma preferia envolver-se com 
atividades que lhe proporcionassem estar em contato com a arte e com a imaginação.

Em entrevista a Gloria Valencia de Castaño, para o programa de televisão Gloria 9h30, no ano de 1976, ao ser questionada sobre como foi sua infância, Emma relata que, às vezes, achava que foi muito triste e, em outras, achava que foi privilegiada. Segundo a autora, tudo o que se passava fora do convento estava ambientado no que chamavam de mundo:

[...] como se estivéssemos em outro planeta. Naturalmente, isso desenvolveu uma enorme imaginação em nós. A nossa imaginação enlouquecia, levando-nos, inclusive, a imaginar que as árvores eram de outra cor e as pessoas de outra forma, e a angústia sobre o que havia lá fora era tamanha que um dia resolvi escapar (GARZÓN, 2016, p. 190).

Dessa forma, pode-se estabelecer uma conexão entre a artista plástica com a menina que bordava no convento, demonstrando-se, assim, as influências dessas vivências na construção de sua identidade. No que diz respeito à sua vida no período anterior ao da chegada à comunidade religiosa, Emma descreveu-se como uma criança que se apoiava na imaginação:

Geralmente me imaginava conversando com o Menino ou com Eduardo ou com os dois; às vezes Helena fazia o papel da sra. María e eu o de Betzabé. Representávamos a sopa comunitária e a d. Inés caindo em cima da panela. Um dia, quisemos encenar o incêndio de Guateque, mas Betzabé apareceu, tirou os fósforos de nós e nos bateu (REYES, 2016, p. 64).

Ao considerar o trecho citado, pode-se ver que até mesmo acontecimentos pesados que via ao seu redor eram subvertidos, transformandose em alvo de brincadeiras e de encenação. O general Rebollo, por exemplo, boneco de barro construído pelas crianças, demonstra essa força da imaginação na construção de algo para transformar uma realidade dura, ainda que por pouco tempo. Dessa maneira, é possivel dizer, também, que o traço imaginativo da personalidade de Emma se refletiu em sua habilidade para a escrita, evidenciada em suas cartas, que se constituíram como texto literário. Sobre seu trabalho como artista plástica, Reyes reconhece essas influências, principalmente a prática com o bordado. Garzón, em sua pesquisa, resgata a publicação Nuestros pintores em Paris, na qual o crítico de arte Álvaro Medina pergunta sobre as pinturas de Emma ao jornalista e diplomata colombiano Plinio Apuleyo Mendoza:

\begin{abstract}
O tema dela eram as pessoas comuns, simples. Embora tenha pintado muitas naturezas-mortas e algumas paisagens, o tema fundamental era o povo da rua [...]. Suas pinturas parecem desenhos coloridos, é a estrutura fundamental que, ela mesma dizia, derivou de sua experiência com os bordados para as freiras (GARZÓN, 2016, p. 200).
\end{abstract}

Apesar de ter trabalhado com Diego Rivera e Frida Kahlo, Emma não conseguiu alcançar o posto alcançado por alguns artistas sulamericanos, com sua obra pictórica. Segundo o crítico de arte Luis Caballero, em um texto sobre a obra de Reyes, "a lenda de Emma surgiu a partir de sua própria vida, apesar de sua obra; é por isso, talvez que sua obra é ignorada". Nas palavras de Arciniegas, "ela não pinta com óleo, mas com lágrimas". Sobre sua arte, Emma diz: "É verdade que a minha pintura são gritos sem ar. Os meus monstros saem da mão e são homens e deuses ou animais ou metade de tudo. Luis Caballero diz que não pinto quadros, mas que os escrevo" (GARZÓN, 2016, p. 200).

Com base nessas considerações a respeito de seu trabalho artístico, pode-se perceber que a arte de Emma está repleta de verdade, em conexão com a essência de seu ser. A expressão "escrever quadros" vem ao encontro da escondida habilidade da artista para a escrita, concretizada na narrativa de suas memórias.

Bonnett se refere à linguagem empregada por Emma como singela, mas não insipida, na narração de coisas que se passaram em outra época, mas que têm a capacidade de gera uma comoção como se estivessem próximas de nós, sem deixar que pesem a violência e a pena. Para a dramaturga, a escrita de Reyes mostra uma força, nascida da voz adulta, recriando, por meio da imaginação, não somente a menina, mas também outras personagens de seu cotidiano de opressão, "retratadas com breves pinceladas": 
Memória por correspondência toca o coração dos leitores por muitos motivos: por seu frescor, por sua capacidade de revelar um mundo sem cair em estereótipos regionalistas, por sua sabedoria na escolha das palavras. Mas, sobretudo, porque seu conteúdo é profundamente humano e poético (BONNETT, 2016, p. 11).

Na opinião do escritor português José Riço Direitinho, Memória por correspondência não impressiona literariamente, mas destaca a sensibilidade poética que transparece nos detalhes ao longo da escrita. Ao recordar os temas que emergem da narrativa, o autor estabelece algumas aproximações e considerações a respeito da escrita de Reyes:

[...] de alguma forma este livro pode fazer lembrar o romance As cinzas de Ângela, de Frank McCourt, e mais umas tantas personagens de Dickens, crianças vexadas, mal-tratadas e abandonadas, e outras que nunca souberam de quem nasceram. Emma Reyes conta: "um dia [...] perguntou-me se eu tinha pai e mãe e eu perguntei-lhe o que era isso e ele disse-me que também não sabia". Mas, ao mesmo tempo, e como nota também Leila Guerreiro, ela pode ser aterradora [...], hilariante (quando the perguntam o nome da mãe e ela responde "loja de chocolates", explícita (quando descreve cruamente como era batida com uma bota) e irónica (ao referir-se a um padre e aos reis da Espanha) (DIREITINHO, [2017]).

Elvia Bezerra (2016), coordenadora de Literatura do Instituto Moreira Salles, em texto intitulado Memória por correspondência? A fabulosa história de Emma Reyes, associa a leitura da obra da artista colombiana ao romance epistolar Os meus romanos: alegrias e tristezas de uma educadora alemã no Brasil, de Ina von Binzer, no qual são retratados os costumes brasileiros na segunda metade do século XIX. Aproximando os dois livros, Bezerra aponta uma sequência cronológica em ambas coletâneas de cartas, por meio da qual se faz possivel a observância da evolução relativa à personalidade e aos sentimentos da narradora.

Germán Arciniegas, em texto intitulado De Flora Tristán a Emma Reyes, publicado no jornal El tiempo, em agosto de 1993, comenta que se Emma tivesse publicado uma história completa sobre sua vida, o livro teria mais leitores do que teve o livro Peregrinações de uma pária, de Flora Tristán. Nessa obra, publicada em 1838, Flora escreve sobre sua viagem ao Peru, trazendo recordações de sua infância. Nas palavras do amigo de Emma, trata-se do "documento mais dramático já deixado por uma mulher em relação a experiências vividas na América" (2016, p. 183).

$O$ destinatário das correspondências de Reyes relembra, ainda, que ele foi quem a persuadiu a escrever suas memórias, conseguindo redigir "umas cem páginas exemplares mesmo que atropelando o castelhano, escrevendo ilusión com c e misturando palavras do francês 'dela' com o que the restava do castelhano 'dela'(2016, p. 185)". Na sua opinião, ela demonstrava ter habilidades para contar histórias, com seus insights de humore inteligência: "quem a escuta gostaria de continuar escutando-a até o amanhecer" (2016, p. 183).

No trecho a seguir, cita-se o final de uma das cartas ao amigo, com uma reflexão sobre o processo de escrever suas recordações:

[...] se você acredita que basta ter ideias, the digo que se a gente não sabe escrevê-las de modo que sejam compreensiveis, é como se não as tivesse. Minha cabeça é como um quarto abarrotado de trastes velhos que não sei mais o que são nem em que estado se encontram (REYES, 2016, p. 103).

Ao refletir sobre essa imagem de um quarto abarrotado de trastes velhos, pode-se compreender que, na tentativa de escrever sobre o que há nele, a autora realiza um processo de reorganização. Nessa perspectiva, considerando que a "reformulação da identidade sempre significa também reorganização da memória" (ASSMANN, 2011, p. 69), é possivel dizer que Emma reestrutura sua identidade, ao recuperar e ordenar recordações por meio da escrita das cartas com as lembranças de sua infância.

Dessa forma, apoiada na perspectiva desse exercício de memória, carregado de subjetividade, a escritora que nasce em Emma oferece um ritmo a seu interlocutor, para que acompanhe a história de uma menina abandonada à própria sorte em meio a uma sociedade que não é complacente ou piedosa. De acordo com o que expressa Chiappe em seu artigo (2017, p. 116), o leitor cumpre o papel de uma testemunha nesse processo, que transforma em palavras o que está guardado na 
mente, na forma de imagem, em conjunto com sensações e sentimentos, relacionados à alma.

Depois de passar por humilhações, discriminações, trabalhos forçados, castigos físicos e até mesmo abuso, ela encontrou uma oportunidade de fugir para o mundo, do qual conhecia muito pouco. A narrativa encontra o seu fim no momento em que Emma consegue abrir a porta do convento, como uma metáfora para representar o momento em que, já adolescente, consegue tomar o controle de seu destino: "Antes de começar a caminhar rumo ao mundo, me dei conta de que fazia muito tempo que deixara de ser menina" (2016, p. 181). Ao partir, fez com que os momentos vividos, presos no convento até então, virassem apenas memórias.

\section{Considerações finais}

Retomando as chaves de leitura propostas para este trabalho, vê-se que as cartas de Emma Reyes cumprem um papel relevante para a memória cultural e para a construção da identidade de seu país, ao resgatar um retrato da sociedade colombiana, no que se refere às problemáticas sociais geradas pela infância de pobreza e de desamparo da autora. Em sua vida adulta, alcançou a possibilidade de intervir em prol dos menos favorecidos, através dos frutos de seu trabalho e de seu talento. Ademais, exalta-se a escrita singela e honesta de uma artista plástica, que conseguiu impressionar os leitores de suas memórias e ganhar o Prêmio de Livro do Ano, na Colômbia, em 2012.

No relato marcado por lugares e por uma trajetória de viagens ao desconhecido, muitas delas representando momentos de dor e de dificuldades para a remetente das correspondências, pôde-se perceber traços que ligam o que Emma viveu quando criança à sua vida adulta, levando-a a escrever as cartas para, de certa forma, realizar um enfrentamento com suas lembranças e, consequentemente, consigo mesma. Através das recordações e dos espaços evocados, dá-se um processo de reformulação de identidade da própria autora, por meio do encontro das vozes da Emma adulta e da criança que foi, na infância rememorada.
Por fim, espera-se que a escrita deste artigo venha a contribuir para os estudos a respeito de Memória por correspondência, considerando que, nessa coletânea epistolar, há mais pontos passiveis de análise e de discussão, além dos que foram aqui mencionados. Salienta-se, assim, o aporte de Emma Reyes à cultura de seu país, por meio da narrativa de suas cartas, no contexto da literatura produzida por mulheres no século $X X$, e de sua obra pictórica. Ainda que tenha dedicado sua vida às artes plásticas, acabou por criar, também, uma obra literária, revelando-se como uma artista que domina, além da arte das imagens e da pintura, a arte das palavras.

\section{Referências}

ÁNGEL, Ricardo Sánchez. Emma Reyes. Memorias por correspondencia. 2. ed. Anuario colombiano de historia social y de la cultura, Bogotá, v. 40, n. 1, p. 359-361, 2013

ARCINIEGAS, Germán. De Flora Tristán a Emma Reyes. In: REYES, Emma. Memória por correspondência. Tradução de Hildegard Feist. São Paulo: Companhia das Letras, 2016. p. 183-186. https://doi. org/10.17533/udea.ef.n54a02

ASSMANN, Aleida. Espaços da recordação: formas e transformações da memória cultural. Tradução de Paulo Soethe. Campinas: Editora da Unicamp, 2011. https://doi.org/10.1590/s0104-87752013000100017

BARNADAS, Joseph. A Igreja Católica na América espanhola colonial. In: BETHEL, Leslie (ed.). Historia de América Latina. São Paulo: EDUSP, 1997. v. 2, p. 185-207

BEZERRA, Elvia. Memória por correspondência: a fabulosa história de Emma Reyes. [S. l.], Instituto Moreira Salles.,2016. Disponivel em: https://www. correioims.com.br/uncategorized/memoria-por-correspondencia-a-fabulosa-historia-de-emma-reyes-por-elvia-bezerra/. Acesso em: 20 jul. 2019 https://doi.org/10.17533/udea.ef.n54a02

BOTERO, Ángela Uribe. Palabrerio y empatia. Sobre Memoria por correspondencia de Emma Reyes. Estudios de Filosofía, Medellín, n. 54, p. 9-22, dez. 2016. Disponivel em: http://www.scielo.org.co/scielo. phppid=S012136282016000200009\&script=sci_abstract\&tlng=es. Acesso em: 20 jul. 2019. https://doi. org/10.17533/udea.ef.n54a02

BONNETT, Piedad. Prólogo. In: REYES, Emma. Memória por correspondência. Tradução de Hildegard Feist. São Paulo: Companhia das Letras, 2016.

CHIAPPE, Doménico. Cartas para levantar la voz. Boletín Cultural y Bibliográfico, [S. L.], v. 51, n. 93, p. 116-117, jan. 2017 
DIREITINHO, José Riço. A incrivel e triste história de Emma Reyes e das freiras desalmadas. Ípsilon, [Portugal], p. [1-4], 11 maio 2017. Disponivel em: https:// www.publico.pt/2017/11/05/ culturaipsilon/noticia/a-incrivel-e-triste-historia-de-emma-reys-e-das-freiras-desalmadas-1788605. Acesso em: 29 jul. 2019

GARZÓN, Diego. O que aconteceu com Emma Reyes? In: REYES, Emma. Memória por correspondência. Tradução de Hildegard Feist. São Paulo: Companhia das Letras, 2016. p. 187-210. https://doi. org/10.17533/udea.ef.n54a02

PREMIO NACIONAL DE PERIODISMO SIMÓN BOLÍVAR. Ganadores por categoria: crónica y reportaje. 2013. Disponivel em: https://premiosimonbolivar. com/ganadores.php? cod=1\$\$-1\$\$-qm4nNEHfto2qtpHLMCVDwz of 2yXG3C6fwm\&edicion=1\$\$-1\$\$-qm4nNEHfZmXaJm98wAU5wqK92yXG3C6fwm. Acesso em: 20 jul. 2019.

REYES, Emma. Memória por correspondência. Tradução de Hildegard Feist. São Paulo: Companhia das Letras, 2016.

RICOEUR, Paul. A memória, a história e o esquecimento. Tradução de Alain François. Campinas: Editora da Unicamp, 2007

\section{Endereço para correspondência}

Nathália Hecz Couto

Pontificia Universidade Católica do Rio Grande do Sul

Av. Ipiranga, 6.681

Partenon 97010-082

Porto Alegre, RS, Brasil

\section{Nathália Hecz Couto}

Mestranda em Teoria da Literatura no Programa de Pós-Graduação em Letras da Pontificia Universidade Católica do Rio Grande do Sul, bolsista CNPq. 